\title{
Intravitreal Bevacizumab May Increase Diabetic Macular Edema in Eyes with Attached Posterior Vitreous
}

\author{
Mustafa Ozsutcu ${ }^{a}$ Gokhan Gulkilik $^{b} \quad$ Emre Ayintap $^{a}$ \\ Muhammed Altinisik ${ }^{a}$ Goktug Demirci $^{b} \quad$ Cengiz Aras $^{a}$ \\ ${ }^{a}$ Department of Ophthalmology, Bezmi Alem Vakif University, and \\ ${ }^{b}$ Department of Ophthalmology, Istanbul Medipol University, Istanbul, Turkey
}

Key Words

Bevacizumab $\cdot$ Diabetic macular edema $\cdot$ Posterior vitreous $\cdot$ Vitreomacular traction

\begin{abstract}
Purpose: To report 2 eyes of a patient which developed vitreomacular traction (VMT) 1 month after intravitreal bevacizumab (IVB) injection. Materials and Methods: A 45-yearold female with bilateral diffuse diabetic macular edema (DME) received bilateral IVB. Results: Her initial visual acuity (VA) was 0.15 and 0.2 in OD and OS, respectively. Central foveal thickness (CFT) was 568 and $662 \mu \mathrm{m}$ in OD and OS, respectively, without any sign of VMT. Both eyes responded well initially but developed VMT at 1 month. This time, intravitreal triamcinolone (IVTA) injection was performed. One month after IVTA injection, VMT was released and CFT decreased to 163 and $181 \mu \mathrm{m}$ in OD and OS, respectively. Six months after IVTA injection, CFT was 163 and $153 \mu \mathrm{m}$, and VA was 0.7 and 0.9 in OD and OS, respectively. Conclusion: In eyes with DME and attached posterior vitreous, VMT may develop after IVB injection and increase edema. IVTA injection might be an option to release VMT before considering vitrectomy.
\end{abstract}

\section{Introduction}

Diabetic macular edema (DME) is the most common cause of moderate vision loss in patients with diabetic retinopathy. Vascular endothelial growth factor (VEGF) has been shown to increase retinal vessel permeability and is a critical stimulus for DME [1]. 
Intravitreal injection of bevacizumab, a monoclonal antibody which targets VEGF, has been shown to provide stability or improvement in eyes with DME [2]. Ocular adverse effects of intravitreal bevacizumab (IVB) include bacterial endophthalmitis, tractional retinal detachment, uveitis, rhegmatogenous retinal detachment, and vitreous hemorrhage [3]. We report 2 eyes of a patient which developed vitreomacular traction (VMT) and increased DME after IVB injection.

\section{Case Report}

A 45-year-old female with type 2 diabetes had a visual acuity (VA) of 0.15 OD and 0.2 OS. Anterior segment examination was normal in both eyes. Fundus examination revealed diffuse DME in both eyes. There was leakage from capillaries and microaneurysms in the perifoveal area and findings of mild proliferative diabetic retinopathy (PDR) on fundus fluorescein angiography examination. Central foveal thickness (CFT), as revealed by optical coherence tomography (OCT) (RTVue; Optovue Inc., Fremont, Calif., USA), was 568 and 662 $\mu \mathrm{m}$ in OD and OS, respectively (fig. 1a, b). OCT analysis was performed in macular thickness map and 6-radial line modes. Neither fundus biomicroscopy nor OCT revealed any sign of VMT. The patient was scheduled for IVB injection, and informed consent was obtained. Both eyes received IVB injection $(1.25 \mathrm{mg} / 0.05 \mathrm{ml})$ at a 1 -week interval. At week 1, VA improved to 0.2 and 0.5 , and CFT decreased to 252 and $436 \mu \mathrm{m}$ in OD and OS, respectively. One month after IVB injection, VA decreased to 0.1 and 0.2 , and CFT increased to 559 and $724 \mu \mathrm{m}$ in OD and OS, respectively, due to VMT, as revealed by OCT (fig. 2a, b). The traction was foveal. This time, intravitreal triamcinolone (IVTA, $4 \mathrm{mg} / 0.1 \mathrm{ml}$ ) injection was performed on both eyes. The patient's VA improved to 0.2 and 0.3 , and CFT decreased to 284 and $173 \mu \mathrm{m}$ in OD and OS, respectively, 1 week after IVTA injection. One month after IVTA injection, VMT was released, as revealed by OCT, and CFT was 163 and $181 \mu \mathrm{m}$, and VA was 0.5 and 0.8 in OD and OS, respectively (fig. 3a, b). Six months after IVTA, CFT was 163 and $153 \mu \mathrm{m}$, and VA was 0.7 and 0.9 in OD and OS, respectively (fig. $4 a, b$ ).

\section{Discussion}

Safety studies have reported the ocular side effects of IVB injection as endophthalmitis, tractional or rhegmatogenous retinal detachment, traumatic injury to the lens, retinal pigment epithelial tears, subretinal bleeding, uveitis, elevated intraocular pressure, retinal artery occlusion, and acute visual loss without apparent reason [3, 5, 6]. Arevalo et al. [7] reported 11 eyes with severe PDR which developed or had progression of tractional retinal detachment after IVB injection. They attributed this to contraction of preexisting membranes. Spaide et al. [8] reported that 1 eye developed VMT out of 20 eyes which had received intravitreal injection of ranibizumab for central retinal vein occlusion. They attributed this to the pathology itself not to the ranibizumab injection.

In the present study, we presented 2 eyes of a patient who had IVB injection for DME which responded well initially but developed VMT at 1 month. The traction developed only at the macula, and other parts of the posterior vitreous were detached. This traction caused massive cystoid macular edema worse than that which had existed prior to injection in both eyes. We believe two possible mechanisms might have played a role in causing the VMT. First, IVB injection might have induced posterior vitreous detachment while firm adhesions at the fovea did not release, thus increasing the macular edema. Second, IVB injection might have increased anteroposterior forces by causing contraction of the vitreous and posterior hyaloid face, increasing the macular edema beyond that of the preinjection state. We believe 
Ozsutcu et al.: Intravitreal Bevacizumab May Increase Diabetic Macular Edema in Eyes with Attached Posterior Vitreous

both mechanisms might have played a role. After IVTA injection, the VMT released and the macular edema resolved in both eyes and remained stable for 6 months of follow-up without any additional intervention. This may support the hypothesis that the posterior vitreous played a role in the etiology of the macular edema prior to IVB injection, and formation of the VMT worsened the edema. The possible mechanism which played a role in the release of VMT after IVTA injection was probably mechanical forces.

In conclusion, in eyes with DME and attached posterior vitreous, VMT may develop after IVB injection and increase edema. IVTA injection might be an option to release VMT before considering vitrectomy.

\section{References}

-1 Nguyen QD, Tatlipinar S, Shah SM, Haller JA, Quinlan E, Sung J, Zimmer-Galler I, Do DV, Campochiaro PA: Vascular endothelial growth factor is a critical stimulus for diabetic macular edema. Am J Ophthalmol 2006;142:961-969.

-2 Arevalo JF, Sanchez JG, Wu L, Maia M, Alezzandrini AA, Brito M, Bonafonte S, Lujan S, Diaz-Llopis M, Restrepo N, Rodríguez FJ, Udaondo-Mirete P; Pan-American Collaborative Retina Study Group: Primary intravitreal bevacizumab for diffuse diabetic macular edema: the Pan-American Collaborative Retina Study Group at 24 months. Ophthalmology 2009;116:1488-1497.

3 Gunther JB, Altaweel MM: Bevacizumab (Avastin) for the treatment of ocular disease. Surv Ophthalmol 2009;54:372-400.

-4 Haritoglou C, Kook D, Neubauer A, Wolf A, Priglinger S, Strauss R, Gandorfer A, Ulbig M, Kampik A: Intravitreal bevacizumab (Avastin) therapy for persistent diffuse diabetic macular edema. Retina 2006;26:999-1005.

-5 Fung AE, Rosenfeld PJ, Reichel E: The International Intravitreal Bevacizumab Safety Survey: using the internet to assess drug safety worldwide. Br J Ophthalmol 2006;90:1344-1349.

-6 Wu L, Martínez-Castellanos MA, Quiroz-Mercado H, Arevalo JF, Berrocal MH, Farah ME, Maia M, Roca JA, Rodriguez FJ; Pan American Collaborative Retina Group (PACORES): Twelve-month safety of intravitreal injections of bevacizumab (Avastin): results of the Pan-American Collaborative Retina Study Group (PACORES). Graefes Arch Clin Exp Ophthalmol 2008;246:81-87.

7 Arevalo JF, Maia M, Flynn HW Jr, Saravia M, Avery RL, Wu L, Eid Farah M, Pieramici DJ, Berrocal MH, Sanchez JG: Tractional retinal detachment following intravitreal bevacizumab (Avastin) in patients with severe proliferative diabetic retinopathy. Br J Ophthalmol 2008;92:213-216.

-8 Spaide RF, Chang LK, Klancnik JM, Yannuzzi LA, Sorenson J, Slakter JS, Freund KB, Klein R: Prospective study of intravitreal ranibizumab as a treatment for decreased visual acuity secondary to central retinal vein occlusion. Am J Ophthalmol 2009;147:298-306.

This study was presented at the 9th Euretina Congress, Nice, France, May 2009.
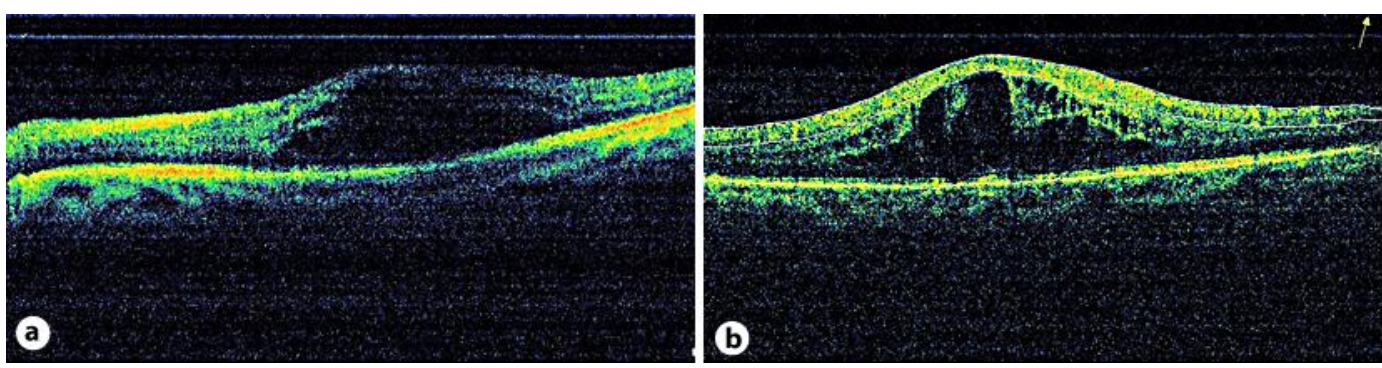

Fig. 1. a, b OCT findings prior to IVB injection. Central foveal thickness was 568 and $662 \mu \mathrm{m}$ in OD and OS, respectively. 


\section{Case Reports in Ophthalmology}

\begin{tabular}{l|l}
\hline Case Rep Ophthalmol 2013;4:7-10 \\
\hline DOI: $\underline{10.1159 / 000342873}$ & $\begin{array}{l}\text { ○ 2013 S. Karger AG, Basel } \\
\text { www.karger.com/cop }\end{array}$ \\
\hline
\end{tabular}

Ozsutcu et al.: Intravitreal Bevacizumab May Increase Diabetic Macular Edema in Eyes with Attached Posterior Vitreous
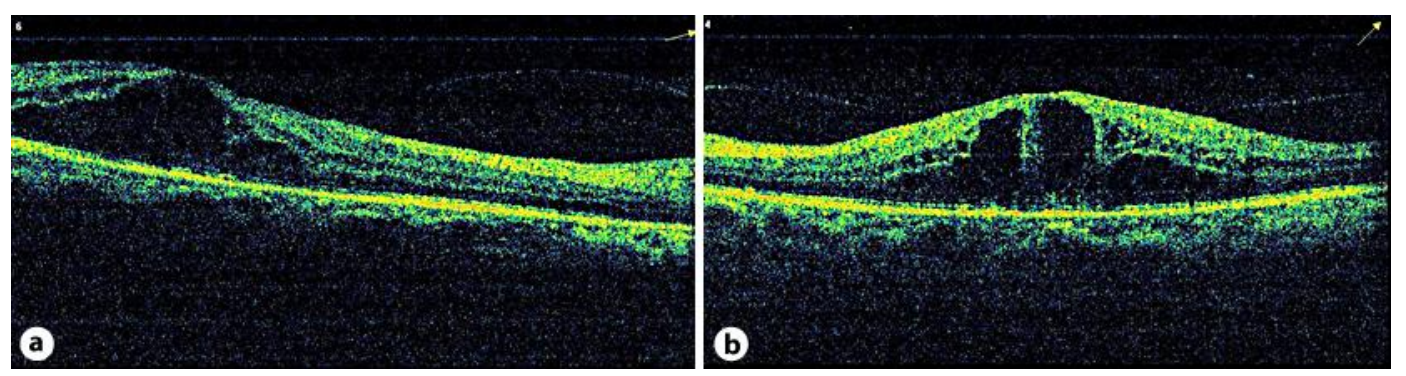

Fig. 2. a, b Findings 1 month after IVB injection. Central foveal thickness increased to 559 and $724 \mu \mathrm{m}$ in OD and OS, respectively, due to VMT, as revealed by OCT.
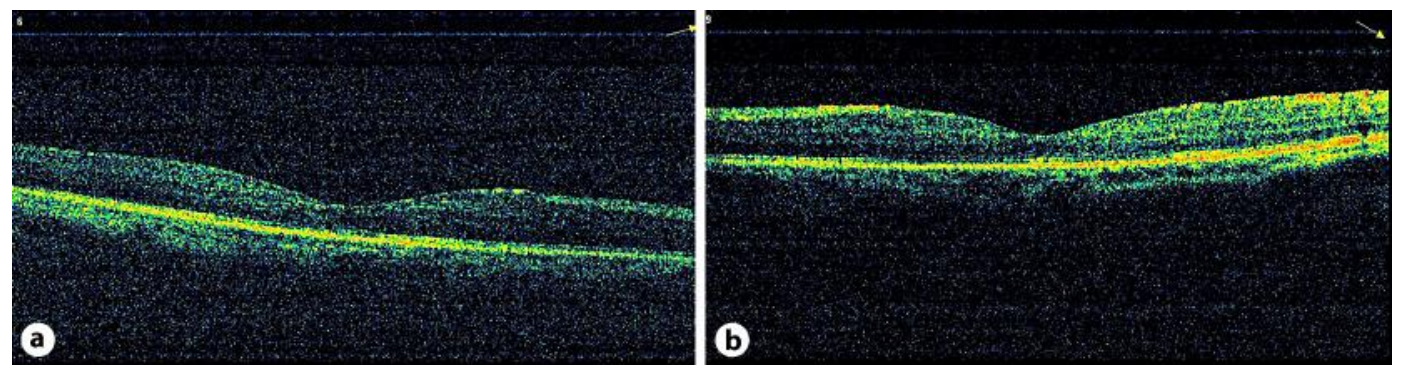

Fig. 3. a, b One month after IVTA injection, VMT was released, as revealed by OCT. Central foveal thickness was 163 and $181 \mu \mathrm{m}$ in OD and OS, respectively.
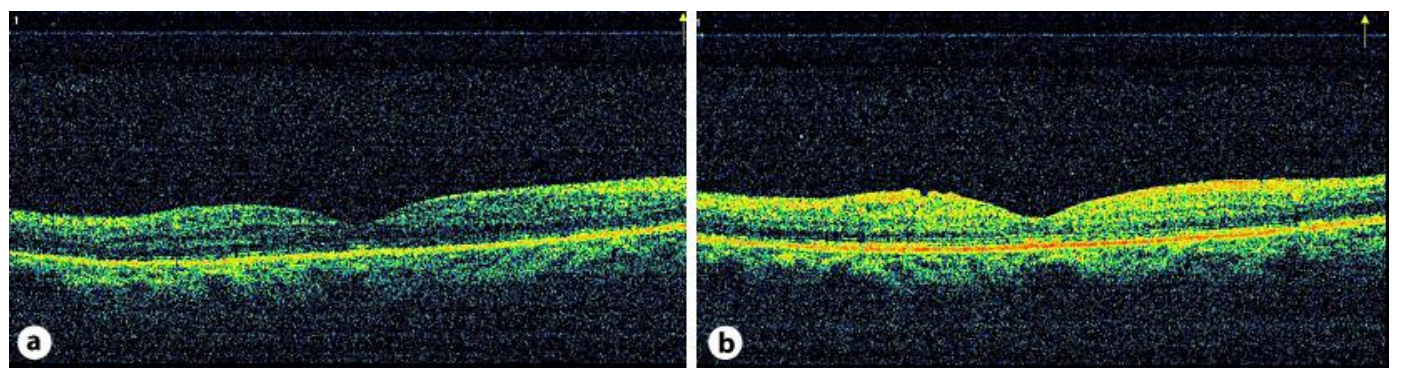

Fig. 4. a, b Six months after IVTA injection, central foveal thickness was 163 and $153 \mu \mathrm{m}$ in OD and OS, respectively. 